András BENEDEK, Budapest and Ágnes TUSKA, Fresno, USA

\title{
Synthesizing the legacy of Varga and Dienes
}

Abstract: Tamás Varga worked closely with Zoltán P. Dienes to provide learners with internally related experiences of creating and discovering abstract concepts, a procedure that Dienes described as "internalized action". In instructing the way Dienes and Varga have promoted, "multiple embodiment" and the cognitive process of the learner in unaccustomed learning situations may be different for teachers and their pupils. Addressing this difference, we outline a lesson for pre-service teachers on comparing divisibility rules in various bases with the use of Dienes's Multibase Arithmetic Blocks as an illustration of how to interface multi-level experiences. In order to answer the didactic problem of how embodied tools augment the learning process by structuring and organizing the learners' experiences at different levels, we point to the principles that make the synthesis of the two innovators' methods possible.

Titel: Synthese des Erbes von Varga und Dienes

Kurzfassung: Tamás Varga arbeitete eng mit Zoltán P. Dienes zusammen, um Lernende zu fördern und ihnen internalisierbare Handlungserfahrungen bei der Erstellung und Entdeckung abstrakter Konzepte zu verschaffen, ein Verfahren, das Dienes als ,internalisiertes Handeln“ bezeichnete. Die Art der Unterweisung, die Dienes und Varga bevorzugten, kann möglicherweise dazu führen, dass die „multiple Verfügbarkeit“ und der kognitive Prozess des Lernens in ungewohnten Situationen für Lehrer und ihre Schüler unterschiedlich sind. Um diesen Unterschied zu verdeutlichen, skizzieren wir eine Lektion für angehende Lehrkräfte zum Vergleich von Teilbarkeitsregeln. Sie soll illustrieren, wie verschiedenartige Verwendungen von Dienes“ „multibase arithmetic blocks“ mehrstufige Erfahrungen miteinander verbinden können. Um das didaktische Problem zu bewältigen, wie verfügbar gewordene Werkzeuge den Lernprozess erweitern, indem sie die Erfahrungen der Lernenden auf verschiedenen Ebenen strukturieren und organisieren, verweisen wir auf die Prinzipien, die die Synthese der innovativen Methoden von Varga und Dienes ermöglichen.

Classification: A60, B59, C30, F60, Q69, U60

Keywords: Tamás Varga, multiple embodiment, Zoltán P. Dienes's principles, multibase arithmetic blocks, divisibility rules, manipulatives, philosophy of mathematics 


\section{Introduction: The problem of different levels}

Tamás Varga (1919-1987) was a defining figure of mathematics education reform in Hungary during the second half of the 20th century. As soon as he was admitted to the Teacher Training Department of Budapest University (ELTE), he faced the need of reforming mathematics education both at the elementary and the teacher training level. "With a reference from his university lecturer, Lipót Fejér, he was awarded a scholarship to spend 18 months at Scuola Normale Superiore, Pisa, Italy. [That] institute developed a system of teacher training similar to that of Scuola Normale Superiore in Paris, namely, to train future teachers, including teachers of mathematics at the highest possible level." (Szendrei, 2007 p. 1)

Zoltán Paul Dienes (1916-2014) was trained as a mathematician and as a psychologist, and he worked on mathematics education-related projects all around the world. He is considered to be the inventor of the Dienes Multibase Arithmetic Blocks and many other games and materials that embody mathematical concepts. Around the time he met Varga, he was a wellknown teaching wizard who demonstrated the success of new, joyful, game-oriented methods with primary school children (Dienes, 1960; Holt \& Dienes, 1974; Dienes, Varga (Ed.), 1989). Varga described the beginning of his long-term collaboration and friendship with Dienes in an article that was published only after his death:

During the nineteen-fifties and early sixties I was charged at the Budapest University with courses on mathematics education to prospective teachers of grade 5 through 12. I felt that my words needed factual support; this is why I decided to test my suggestions with an average group of pupils from grade five in five weekly hours. After three years of our intensive work, Z. P. Dienes arrived on the scene during the summer of 1960. He came from Cracow where he had participated at a meeting of the CIEAEM. In Budapest he delivered a lecture at the Second Hungarian Mathematical Congress (where I, too, reported on my experiences), and conducted some demonstration lessons. What he told and showed us convinced me of the necessity of a new start, one with younger children and a completely different organization. (Varga, 1988, p. 291, emphasis added.)

The two innovators of math education were faced with a pedagogical dilemma. Accepting that Dienes's new methods, augmented by manipulatives, games, and embodied learning should be introduced in schools, teacher training needed reorganization to change teachers' attitudes. (Dienes, 1995/2007, p. 2; Servais \& Varga, 1971, pp. 242-244) But how could these attitudes be changed if the teachers themselves, including pre- 
service teachers and their teachers, were taught in the spirit of the goodold-fashioned methods? Dienes summarized his major accomplishments in mathematics education during an interview the following way:

My emphasis was on the use of mathematical games with appropriate learning aids (manipulatives), work, and communication in small groups with the teacher overseeing these groups. [...] What I have been doing for over 50 years is not so much outside social issues but critical thinking about what mathematics is and what it can be used for and to have it presented as fun, as play, and in this sense it can be self-motivating because it is in itself a fun activity. I have critiqued mathematics being presented as a boring, repetitious activity as opposed to a way to think [...] a way to train the mind, [...] understand patterns and relationships, in ways that are playful and fun. (Sriraman \& Lesh, 2007 p. 62-64)

The "way to train the mind" that Dienes refers to incorporates a didactic problem, in addition to the above mentioned pedagogic dilemma of the educationalists. Teaching in the way as Dienes (1960; 1995/2007) described implies placing ourselves into the learners' position who face an unknown situation at a different level of abstraction and with a different history of personal experience than their teacher. Immersion into the concept-forming situations of the games and in the potential proceedings of the learners' thoughts requires not only empathy but acquaintance with unaccustomed situations, a quite different experience than many pre-service teachers and their teachers obtained during their schooling. Pre-service teachers enter these situations with different preconceptions, different level(s) of abstraction, and work on the basis of distinct previous personal knowledge of their own. If they want to enter the spirit of the learners' problems, their 'background knowledge' should not consist of only an enriched understanding of the subject matter based on their own schooling experience. Teachers need to clarify the problems and their nature from the learners' point of view by distancing, or even disconnecting, themselves from their present knowledge. Understanding what makes it possible for their pupils to hold their beliefs as true requires the exploration of the affordances of the manipulatives and acting upon them with the learners accordingly. Inventing, playing, and varying the games results in questions and answers that cultivate re-thinking the meaning of terms that arise out of the need to expose the foundations of discourse upon which the teacher acts collectively together with the learners. This situation requires the introduction of new methods into teacher training that force pre-service teachers to live through similar experiences that they are supposed to provide, making 
them understand the alternatives of the uninitiated mind and reconsider the possible paths to personal knowledge. In Varga's and Dienes's times, lecturing and whole class instruction was usually assumed and these circumstances rarely made possible consideration for the learners' personal paths of thoughts seeking sense in new problem situations. "The teacher training - both the initial and the inservice training - should serve to remedy the situation, but their efficiency is not spectacular. Much depends on the trainers, of course." (Varga 1988 p. 294) Drawing the "skeleton", which helps to progress from one stage of development to another, Dienes (1964a, 1995/2007) spelled out the didactic principles of building up the students' abstractions at different levels and illustrated how they work. Since he believed that in any un-accustomed problem situation, essentially the same kind of steps of abstraction has to be made from one level to the other but along the personal paths of discovery (Dienes, 1995/2007 p. 17), the question arises: Would the application of the principles of Dienes be as efficient in teacher training as in the education of children? We argue that the answer is yes by outlining a lesson below as a sample to show these principles in action.

\section{Manipulatives at different levels of embodied learning}

Varga prepared texts of sample lessons from around the world to illustrate methods of dealing with certain subjects. The very first lesson he included in a UNESCO source book was a lesson in logic, given by Dienes with extensive use of group work, visuals, and the Dienes variant of Vygotsky's logic blocks (Servais \& Varga, 1971, pp. 38-46). Dienes's innovative approach meant much more than just the use of manipulatives. He was a rarely mentioned pioneer of embodied learning in the sense of the recent cognitive psychological revivification of the term (cf. Barsalou, 2008a, p. 619) who combined human activity not just with manipulatives but all the affordances of the learning environment. Manipulatives were key features in lessons promoted by Dienes and Varga besides activity-based personal experience and small group interaction. The use of manipulatives helps to organize and structure the learner's experience, and enhances communication and discussion with peers and learning facilitators through a wider range of modalities. Manipulatives assume some targeted meaning with built-in, predesigned affordances. ${ }^{1}$

${ }^{1}$ There are two different definitions of manipulatives in the literature: 1 . any concrete object that may facilitate learning; and 2. pre-designed objects with intended use. Although Dienes was able to use even a river shore as a "manipulative" for exploring 
The same is true for graphics, diagrams, models, and many other tools:

They externalize thought and thereby promote thought. Taking ideas that are in the mind out of the mind and putting them into the world in front of our eyes helps our own thinking and that of others. Putting thought into the world is key to collaboration, to working together, to the joint action that is core to human society, and to survival. (Tversky, 2019 p. 284)

There is an extensive collection of evidence that children benefit from the appropriate use of manipulatives. (Moyer, 2001, Kwon \& Caprano, 2018) Moreover, some studies have shown student achievement levels to be related to teachers' experience in using manipulatives (Moyer, 2001, p. 177). Are the same manipulatives useful for adult learners as for children? Can we provide challenges for prospective teachers where they will benefit from using the same manipulatives as they are expected to use with children? How could we interface the learning experience of pre-service teachers with the experience of their pupils?

A specific difficulty Varga encountered working with teachers inspired us to design our sample lesson for prospective elementary teachers:

Imparting new knowledge is relatively easy. Difficulties arise when trainees are supposed to unlearn obsolete concepts, to abandon familiar views, to change habitual practices, or - most difficult though most important of all - to change their attitudes. I mean, for instance, accepting children as fellow-learners whose ways of thinking, silly as they seem, merit serious attention - not a standard attitude on the part of Hungarian teachers, I must say. (Varga, 1988, p. 294, emphasis added.)

We chose the topic of the lesson to be the exploration of divisibility rules in various bases. Most undergraduates are familiar with many divisibility rules in base ten, but have never experienced formulating rules in other bases. Therefore, they may lack the understanding of why and how divisibility "rules" work and how they depend on the representation of numbers. As Varga wrote:

Experience, said Comenius, should be the starting point. [...] [T]he exposition of ready-made knowledge and the overemphasis on verbal memory as opposed to experience and understanding are all too frequent today, even

topological problems, he considered manipulatives as tools carefully crafted for intended problem situations in "artificial mathematical environments" "so devised that through interaction with them certain mathematical concepts are formed." (Dienes, $1995 / 2007$ p. 112) 
in mathematics teaching. (Servais \& Varga, 1971 p. 13) ... Among the ingredients of new school mathematics, there is hardly any more important than leading pupils to meet mathematics in statu nascendi, or to make them rediscover it. (ibid, p. 27)

Both Dienes and Varga attached special importance to facing genuine problems and bewildering questions in "unexpected situations" as opposed to "rote learned mathematics". (Dienes, 1995/2007 p. 30) The role of a "surprising idea, one that shocks the child, one that he would have thought differently" [...] "is to puzzle the children" and to put them in an unaccustomed situation in which they are "more likely to think independently". (Servais \& Varga, 1971, pp. 20-21). The point of the lesson plan is to put prospective teachers into a learning situation in which they have to abandon their comfort zone of base ten representation of numbers and the corresponding division rules. We introduce a game in a higher base so they may discover the relevant features of number systems on which the rules depend. This way, the students have to go along similar pipelines of internalizing mental operations by the manipulatives that they use as their prospective pupils will, in exploring lower bases. Given this experience, they are expected to invent similar games for their pupils. As Dienes (1995/2007 p. 20) puts it:

What could be a better preparation for "doing mathematics" than the playing of various games with rules? In order to give the games some mathematical value, we merely have to construct materials and make up the rules of the game in question to correspond to the properties of the structure we wish children to learn. If the game is motivating, children will want to play it, and we shall not have to stand behind them to make sure that they "do mathematics".

In the outline of the lesson, we highlight the application of the principles of building abstract concepts that Dienes (1995/2007 p. 17) considered crucially important for cultivating the development of cognitive processes of understanding not just for children but for anyone facing unaccustomed problem situations in a new field. We refer to Dienes's principles, summarized in Benedek (2018) using Dienes's latest terminology (Dienes, 1995/2007).

\section{A sample lesson for prospective elementary school teachers}

In the envisioned class, about 25 prospective elementary school teachers sit around tables in groups of 3 or 4 . Each group has access to buckets of colored multi-link cubes, so that they can build arithmetic blocks of any 
base $^{2}$ and small white boards with pens. The class is equipped with a document camera and a large white board. The instructor displays through the document camera the introductory question: Which propositions are true in base 5? (A) 4 divides 444; (B) 4 divides 234; (C) 4 divides 121; (D) 4 divides 144. Students are to write down their opinions on their small whiteboards. The instructor opens a whole-class discussion of the responses. (Multiple experience, Constructivity Principle of Dienes). Anticipated responses include arguments and reflections such as: "Since 444 includes 4 of everything, it must be divisible by 4." "I realized that 234 represents an odd number because I add 3 fives to the sum of two even numbers, so it has no chance to be divisible by 4 ." "I thought that 121 will be an odd number, but, when I converted it to base ten, I realized that it is 36 , so it is divisible by 4." "Although 144 is divisible by 4 in base ten, it is not divisible in base five." (Deep-End Principle of Dienes ${ }^{3}$ in action: students are really forced to think about what is happening and what determines whether a number is divisible by another or not. Key discovery: Whether a number is divisible by 4 or not is independent from the representation of the number. However, the rules of divisibility, e.g., by 4 , are dependent on the properties of the number representational system and not on the number itself.

Next, the instructor asks the students to represent 234 by arithmetic blocks, and to show the manipulation for obtaining the remainder when the number is divided by 4 . Some students may report taking off chunks of 4 multi-link cubes from each of the 2 five by fives (flats) and 3 fives (longs), ending up with seventeen individual cubes, which is enough to form another 4 fours, with 1 cube remaining. Others may have recognized that each of the 2 five by fives (flats), the 3 fives (longs), and the 4 ones (units) are exactly 1 more than some many fours, therefore, the remainder that 234 gives when divided by 4 is exactly the same as the remainder what the sum of the digits

\footnotetext{
${ }^{2}$ Dienes never intended his "multibase" arithmetic blocks (exclusively) for base ten in the widespread commercial form of fixed longs and flats. (Cf. Dienes 1964b, p. 79; Dienes, 1995/2007, p. 9) The coloured multi-link cubes provide a wider range of affordances for understanding the concept of place value and number systems than the fixed longs and flats which make exploring the idea of grouping harder with their "ready-made" formations. The colours and the connectivity of the multi-link cubes emanate further abstractions.

3 "Throwing them in at the deep end" is a policy, where the more complex structure is introduced first - in which the simple structure is included as a sub-case, as a part of the more extensive structure - as opposed to proceeding to the more complex through "step-by-step" construction or extrapolation of the general pattern, from which the simple case can be deduced. (Dienes \& Jeeves, p. 97)
} 
of 234 gives when divided by $4 .^{4}$ This observation gives a good opportunity to ask questions about analogy with known divisibility rule in base ten (divisibility by 9 and 3 was checked by the sum of the digits there) and about potential generalizations (divisibility by the quantity $n-1$ in base $n$ will always depend on the sum of the digits). Playing with the arithmetic blocks at this stage was what Dienes characterized as exploratory-manipulative type of play. Dienes claimed that manipulative play may quite imperceptibly move over to a search for regularities (Dienes, 1963 p. 23), as it led to the formulation of a divisibility rule in our case.

Then the instructor sets the following task for group work: "You are aware of many divisibility rules in base ten. For example, a number is divisible by 4 if the two-digit number, formed by the last two digits of the number is divisible by 4 . Try to state divisibility rules in base five for various divisors! Justify your rules!" (Perceptual Variability Principle of Dienes: varying the divisor. Key question: How do mathematical insights become intersubjective through human activities?)

The construction of a rule for divisibility by 3 in base five may lead students to invent color-coded representation of positive or negative remainders, such as, the "long", representing 5 is one short of two 3's, therefore, can be said that it gives negative 1 as a remainder when divided by 3 . (The multibase blocks may again serve as a crutch here just as in the card game below.) This is an example of a representational play, where objects are assigned properties different from those they in fact have (Dienes, $1963 \mathrm{p}$. 24). It can lead to formalization and experience-based introduction of symbolic representation for modular arithmetic: the "flat" is made of 5 longs, therefore, it will give 5 times (-1) remainder when divided by 3 , which is $(-5)$, giving the remainder which is the opposite of the remainder of 5 , so must be positive 1 . In the language of congruences, $5(-1)$ is congruent to 1 modulo 3. Applying the principles of Interdisciplinarity and Multiple Embodiment to abstractive learning, Dienes's (1995/2007, p. 9-12) method of representing remainder classes by bodily arm positions and musical tunes can be introduced for children. It challenges the students to extend it to negative numbers.

In order to expose students to bases larger than ten and to have them experience the kind of unaccustomed situation in which their pupils may find themselves exploring the rules in lower bases (or even in base ten), the lesson

\footnotetext{
${ }^{4}$ See some pictures of the manipulatives representing this line of reasoning and the card game below at http://heurisztika.btk.mta.hu/en/resources/pictures/76-picture
} 
would end by playing the following card game (for 2 or 3 players): Take a deck of 52 cards plus 4 jokers to represent digits in base fifteen as follows: $2=2, \ldots 10=10, \mathrm{~J}=$ eleven, $\mathrm{Q}=$ twelve, $\mathrm{K}=$ thirteen, $\mathrm{A}=$ fourteen $\mathrm{OR}$ one, Joker $=$ any digit (including the digit 0 ). Each player receives 12 cards from a shuffled deck (with jokers added). One card is turned up from the deck to represent the requested divisor. Players take turns. When it is their turn, they pull a card from the deck or pick up the card the previous player discarded, and put down some or none of the cards in their hands as 1-, 2-, 3- , 4-, 5-, or 6-digit numbers that are divisible by the divisor and discard one card. The player who can first get rid of all her cards wins.

The above game is a rule-bound play. Of the three types of plays (manipulative, representational, and rule-bound), Dienes claimed that "clearly the rule-bound type is the most suitable as a point of interference or 'teaching' in order to use the play energy in the service of higher-order cognitive activity" (Dienes, 1963 p. 31).

The assigned homework is to devise another rule-bound game that promotes the understanding of certain divisibility properties (by their pupils) and to describe the rules of the game. The game should be tried out with children. The strategies and reflections of the children need to be recorded.

The discussion of this homework assignment, in particular when the question is raised of how to teach the same material to children, can lead to the development of a series of games designed for pupils with colored multilink cubes, where different meanings of color coding is developed. Differentiating longs and flats according to their color (a green flat means three flats, a red flat means five flats, etc.), they learn that the affordances of the multi-link cubes can be utilized in different ways, making them aware that their usage is not self-evident for their pupils either. Later "flatness" may be represented by the (second) position of a single cube in colored "trains" of little cubes, perceived as colour coded digits in a system that carries over the meaning of "long", "flat", etc. to the position. The trains correspond to the series of cards representing numbers in different bases in the card game above. They not only map isomorphically the place value structure of the cards (whose figures may distract the attention of children) but, exchanged with the cards, also provide multimodal experience according to the variability principles. Inventing games both with multi-link cubes and cards challenges the students to design games that "build up" the number concept and the divisibility rules in a constructive way for those students who are 
not analytically minded. ${ }^{5}$ This way, prospective teachers can prepare for developmental differences and become able to work appropriately with different types of learners by considering their personal learning history.

\section{Synthesis}

Dienes, unlike Piaget and Skinner, observed very early that individual development reveals different thinking styles and learner types. Moreover, he realized that mathematical understanding and its verbal expression are heavily dependent on the individual's personal learning history and experience. Both Dienes and Varga were aware of the pedagogical and didactic dilemma of teaching and learning at different levels and the challenging task of changing teachers' attitudes by interfacing teacher training and school teaching. They exerted considerable effort to promote an educational reform in a number of experimental areas, including various methods of game-oriented joyful learning, the use of manipulatives, and small group teaching. Their attitude of discovery learning concentrated on the curriculum reform not so much for including new mathematical fields but for promoting the "thinking style" of modern mathematics in any areas that the learning path may encounter. Their commitment to embodied learning arose from their "maverick philosophy of mathematics" (Cellucci, 2017), which is based on the conviction that mathematics is human activity emanating in constructive steps and intuitive analogical leaps of abstraction that can be assisted by properly applied principles. Our synthesis of their work involves domain dependent reconsideration of the affordances of the used manipulatives which are to be adjusted to the learners' abstraction level and background knowledge. Learning this ability assumes that the games that are introduced in teacher training explore the domain and the guidance opportunities in such a way that the students realize that they need to develop a competency, themselves, to handle unaccustomed situations in which they guide their pupils to find the crucial insights into the problems via their own abstractive moves. In "building up" these abstractions, Dienes's principles are there to help and enhance guided discovery at both the teacher training and at the school level. They can and should be applied at different levels (differently) while learners explore the pathways leading to higher levels of abstraction (both in the case of teachers and their pupils). The conviction of Dienes and Varga for using real-world objects, mani-

\footnotetext{
${ }^{5}$ Dienes suggested applying e.g., the deep-end principle in case of analytically minded students but constructive methods in case of others. Cf. International Study Group for Mathematics Learning (1966), p. 52.
} 
pulatives, games, and plays including movements and activities of the human body in mathematical explorations (Holt \& Dienes, 1973; Dienes \& Varga, 1989) is backed up by now by embodied cognition research (Pouw et al., 2014). These results imply reconsidering the causal relevance of statistical studies that measure the effectiveness of using manipulatives in a field where just as much depends on the "how" than on the "what". Human abstractions are, in large extent, grounded in sensory-motor experience (Barsalou, 2008b). Abstract ideas, including mathematical concept developments, make use of grounded cognitive mechanisms such as conceptual metaphors, visualizations, simulations, etc. that import modes of reasoning from sensory-motor experience (Lakoff \& Nunez, 2000 p. xii; Tran et al., 2017).

Requesting explanations from the learners instead of spending class time on lecturing by the instructor has a research-based rationale. As Tversky reports, after junior high students were taught and tested on a STEM concept, the students were divided into two groups. Students in one group were asked to make visual explanations and those in the other group to make verbal explanations. Then a second test was given. Both groups improved their test performance simply by creating explanations. Those who created visual explanations showed far greater improvement than those who explained verbally (Tversky, 2019 p. 260). We conjecture that research with adult learners may lead to similar results and further differentiation of learners' types. As we promoted in our sample lesson, teacher training should put ample emphasis on providing opportunities for participants to reflect on their own learning (including the ways learning principles apply to themselves) not only verbally, but through collaboration on designing good visuals, games, and other tools to augment the learning process for themselves, for their peers, and for their future students.

Dienes was a "teaching wizard" who "embodied" the desired end-result of an effective teacher training, while Varga "held the hands" of teachers along the strenuous road to "get there". As "mavericks", they studied every aspect of the learning process and the humans involved in it in entirety with the utmost respect and curiosity. Their combined legacy remains a driving force of the best attempts and theories in reforming mathematics education to date.

\section{References}

Barsalou, L. W. (2008a). Grounded cognition. Annual Review of Psychol., 59, 617-645.

Barsalou, L. W. (2008b). Grounding symbolic operations in the brain's modal systems. In G. R. Semin \& E. R. Smith (Eds.), Embodied grounding: Social, cognitive, affective, and neuroscientific approaches (p. 9-42). Cambridge Univerity Press. 
Benedek, A. G. (2018). Embodied Conceptions of Mathematical Understanding in the Twentieth Century: the emergence of Zoltan P. Dienes's principles and their origin. In Péter Körtesi (ed.) Electronic Proceedings of the History of Mathematics and Teaching of Mathematics, Miskolc, Hungary 2018. May 23-26. Miskolci Ifjúsági Matematikai. Egyesület

Cellucci, C. (2017). Varieties of maverick philosophy of mathematics. In Humanizing mathematics and its philosophy (pp. 223-251). Basel: Birkhäuser, Cham.

Dienes, Z. P. (1960). Building up mathematics. London: Hutchinson.

Dienes, Z. P. (1963). An experimental study of mathematics-learning. London: Hutchinson.

Dienes, Z. P. (1964a). The power of mathematics. A study of the transition from the constructive to the analytical phase of mathematical thinking in children. London: Hutchinson Educational.

Dienes, Z. P. (1964b). Mathematics in the Primary School. Adelaide: Griffin Press.

Dienes, Z. P. (1995/2007). Some thoughts on the dynamics of learning mathematics. In Bharath Sriraman and Lyn D. English (eds.) The Montana Mathematics Enthusiast (pp. 1-118). Missoula, MT: The Univ. of Montana Press.

Dienes, Z. P. \& Jeeves, M. A. (1965). Thinking in Structures. London: Hutchinson.

Dienes, Z, Varga, T. (ed.) (1989). Dienes Professzor Játékai [The games of Professor Dienes]. Budapest: Müszaki Kiadó.

Holt, M. \& Dienes, Z. P. (1973). Let's Play Maths. London: Penguin Books.

International Study Group for Mathematics Learning (1966). Mathematics in primary education. Learning of mathematics by young children. Compiled by Zoltan P. Dienes. UNESCO Institute for Education, Hamburg.

Kwon, H. \& Caprano, M. M. (2018). The effects of using manipulatives on students' learning in problem posing: The instructors' perspectives. Journal of Mathematics Education, 11(2) 35-47.

Lakoff, G. \& Núñez, R. E. (2000). Where mathematics comes from: how the embodied mind brings mathematics into being. New York: Basic Books.

Moyer, P. (2001). Are we having fun yet? How teachers use manipulatives to teach mathematics. Educational Studies in Mathematics, 47, 175-197.

Pouw, W. T., van Gog, T. \& Paas, F. (2014). An embedded and embodied cognition review of instructional manipulatives. Educational Psychology Review, 26, 51-72.

Servais, W. \& Varga, T. (1971). Teaching School Mathematics. Penguin Books: UNESCO.

Sriraman, B. \& Lesh, R. (2007). Leaders in Mathematical Thinking \& Learning- A conversation with Zoltan P. Dienes. Mathematical Thinking and Learning: An International Journal, 9(1), 59-75.

Szendrei, J. (2007). In memory of Tamas Varga. http://www.cieaem.org/?q=system/files/varga.pdf

Tran, C., Smith, B., \& Buschkuehl, M. (2017). Support of mathematical thinking through embodied cognition: Nondigital and digital approaches. Cognitive Research: Principles and Implications, 2: 16. DOI 10.1186/s41235-017-0053-8

Tversky, B. (2019). Mind in motion: how action shapes thought. New York: Basic Books.

Varga, T. (1988). Mathematics education in Hungary today. Educational Studies in Mathematics, 19(3), 291-298. 